\title{
Adamantane-Modified Graphene Oxide for Cyanate Ester Resin Composites with Improved Properties
}

\author{
Zhicong Miao ${ }^{1,+}$, Juntao Shi ${ }^{1,+}$, Tianjiao Liu ${ }^{1}$, Peng $\mathrm{Li}^{1, *}$, Zhiqiang Su ${ }^{1, *}$ and Gang Wei ${ }^{2, *}$ \\ 1 State Key Laboratory of Chemical Resource Engineering, Beijing Key Laboratory of Advanced Functional \\ Polymer Composites, Beijing University of Chemical Technology, Beijing 100029, China; \\ 18810867810@163.com (Z.M.); buctshijt@sina.com (J.S.); 2016200362@mail.buct.edu.cn (T.L.) \\ 2 Faculty of Production Engineering, University of Bremen, D-28359 Bremen, Germany \\ * Correspondence: lipeng@mail.buct.edu.cn (P.L.); suzq@mail.buct.edu.cn (Z.S.); wei@uni-bremen.de (G.W.) \\ + These authors contribute equally to this work.
}

Received: 22 January 2019; Accepted: 23 February 2019; Published: 1 March 2019

check for updates

\begin{abstract}
The conjugation of graphene and polymers has attracted great attention for the fabrication of functional hybrid nanomaterials. Here, we demonstrate the modification of graphene oxide (GO) with adamantane (AMT) through the diimide-activated amidation reaction. The modification of GO with AMT improves the dispersion and decreases the interfacial polarization of GO, causing a lower dielectric constant for the fabricated GO/AMT hybrid materials. The structures of GO/AMT were studied by Fourier transform infrared spectroscopy and Raman spectroscopy. Furthermore, the mechanical properties, thermal stability, and dielectric constant of GO/AMT composites were measured at a low cured temperature using various techniques, such as differential scanning calorimetry, thermogravimetric analysis, and dynamic mechanical thermal analysis. It was found that the synthesized GO/AMT materials with different contents were blended into cyanate ester (CE) resins, resulting in a lower cure temperature, smaller dielectric constant, higher thermal stability, and stronger water resistance. It is expected that this novel GO/AMT-CE material will have potential applications for replacing traditional thermosetting resins.
\end{abstract}

Keywords: adamantane; graphene oxide; cyanate esters; dielectric constant; thermal properties

\section{Introduction}

Cyanate esters (CEs) are one kind of high-performance thermosetting resins, which have many advantages, such as high glass transition temperatures (Tg) (from 250 to $300{ }^{\circ} \mathrm{C}$ ), good mechanical properties, high fracture toughness, and low moisture absorption. In addition, the dielectric properties of CEs are superior to all other existing thermosetting resins [1-3]. All the above advantages permit CEs to be well-suited materials for application in the fabrication of electrical components, aerospace structures, and adhesives, as well as the design of many functional composites [3-5]. Nevertheless, CEs also have some disadvantages, such as a high cure temperature and brittle structure, which limits their applications in many fields. To overcome the disadvantages of CEs, one of the facile method is to modify CEs to improve their overall performance [6-11]. The most common method is to blend CEs with epoxy resins, by which the mechanical properties of the CEs system can be improved $[12,13]$. Unfortunately, this modification method will inevitably decrease the heat resistance and other vital properties of CEs [14-16].

The unique electronic, thermal, and mechanical properties of graphene make it a potential candidate to improve the functions and properties of many polymer materials [17-20]. Even a low dosage of these single-layer carbon nanosheets will provide polymer composites with excellent chemical and physical properties. However, the poor dispersion of graphene limits the interface 
interaction between graphene layers and polymers [11,21,22]. Graphene oxide (GO) has the same framework structure as graphene and is easier to synthetize. In addition, the abundant oxygen-containing groups of GO make it readily modifiable, and the surface modification of GO allows better dispersion [23-26]. Therefore, the combination of GO and polymers offer the new composite structures and additional properties. For instance, Xue et al. reported that the functionalization of GO with polyhedral oligomeric silsesquioxane (POSS) promoted the solubility of POSS-GO in various organic solvents. They used the POSS-GO as a novel nanofiller for interfacial reinforcement with poly(methyl methacrylate) (PMMA) and found that the addition of only $1 \mathrm{wt} \%$ POSS-graphene into PMMA could increase the Tg of the resultant composite by more than $10^{\circ} \mathrm{C}$, along with a significantly increased thermal stability [27]. Similarly, Liu et al. designed a novel polyethyleneimine-modified GO by solution-casing for facilitating a homogeneous dispersion of GO in a polyvinyl alcohol (PVA) matrix [28]. To improve the dispersion and the strength of a filler-matrix interface in acrylic resin, Dong et al. obtained $\gamma$-methacryloxypropyl trimethoxysilane-functionalized GO by surface modification [29]. Mazzoli et al. found that the synergistic effects between GO particles and short steel fibers as fillers improved the mechanical properties and electromagnetic shielding efficiency of the cementitious composites [30].

A widely used chemical, adamantine $\left(\mathrm{C}_{10} \mathrm{H}_{16}\right)$ (AMT) is a highly symmetrical and very stable hydrocarbon [31-35]. The internal atomic structure in the molecule of adamantine is similar to the portion of the diamond lattice of carbon atoms, leaving it to be a very stable and rigid group. As an important intermediate, AMT has been widely used in many fields, such as medicine, functional polymers, lubricants, catalysts, surfactants, photographic materials, and pesticides, to name a few [36-39].

Previously, Lin et al. found that the GO/CE composites exhibited better mechanical, tribological, and thermal properties [40]. Zhang et al. reported an efficient and novel method to functionalize GO with hyperbranched polysiloxane and successfully compound them with CE resin to prepare nanocomposites [41]. In this study, we covalently grafted AMT onto GO sheets via the amide formation between amine-functionalized AMT and the carboxyl groups of GO. The resultant GO/AMT hybrids were found to be well-distributed in the CE resin. The GO/AMT hybrids with different contents were blended with CE resin to enhance the resin performance on their mechanical, thermal, dielectric, and water-resistant properties. The combination of GO/AMT and CE for the formation of GO/AMT-CE composites is shown in Scheme 1. First, the $\pi-\pi$ stacking of benzene rings promoted the non-covalent bonding between GO and resin. Second, the cyclization of -OCN and -OH or C-O-C resulted in the formation of three kinds of rings: oxazoline rings, isocyanurate rings, and oxazolidinone rings. Third, the triazine rings were formed by the resin itself. These three steps promoted the continuous growth of the resin, and the GO sheet layer served as a growth site to further increase the crosslink density of the resin. We suggest that the addition of GO/AMT decreased the reaction temperature and broadened the exothermic peak, benefiting the manufacture processing of CE.

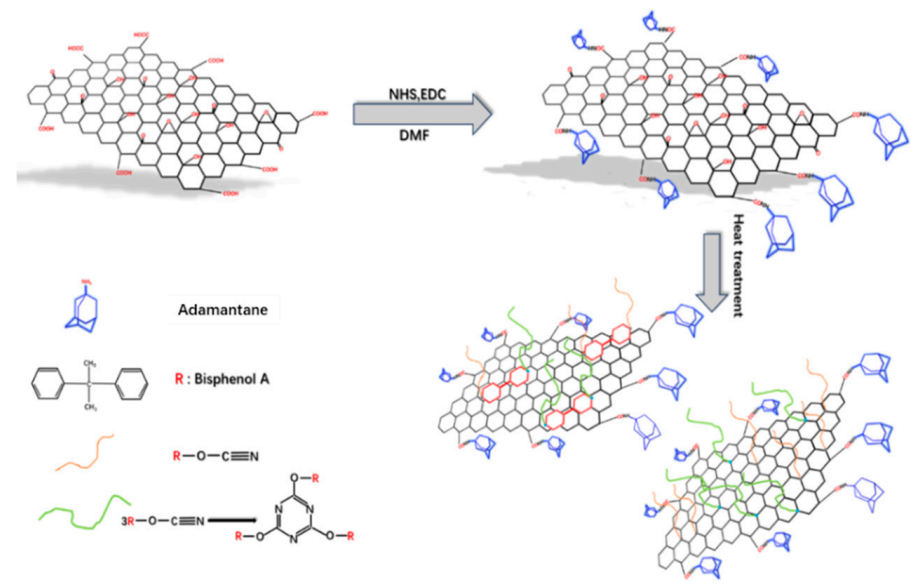

Scheme 1. Illustration of the formation of adamantine/graphene oxide-cyanate ester (AMT/GO-CE) composites. 


\section{Materials and Methods}

\subsection{Regents and Materials}

Natural graphite flake (99.8\% purity) was obtained from Alfa Aesar. $\mathrm{H}_{2} \mathrm{SO}_{4}\left(95-98 \mathrm{wt} \%\right.$ ) and $\mathrm{KMnO}_{4}$ (99.5\% purity) were purchased from Beijing Chemical Co., Ltd. (Beijing, China). $\mathrm{H}_{3} \mathrm{PO}_{4}$ (85\% purity) and $\mathrm{H}_{2} \mathrm{O}_{2}(30 \%$ aqueous solution) were obtained from Xilong Chemical Co., Ltd. Adamantan-1-amine (98\% purity), N-Hydroxysuccinimide (NHS), and 1-(3-Dimethylaminopropyl)-3-ethylcarbodiimide hydrochloride (EDC) were supplied by J\&K Chemical (Beijing, China). Bisphenol A type cyanate ester (BCE, $\mathrm{Mn}=278.30 \mathrm{~g} / \mathrm{mol}$ ) was supplied by Malt Chemicals (Jiangsu, China). The other reagents such as $\mathrm{HCl}(10 \mathrm{~mol} / \mathrm{L}), \mathrm{NaOH}(\mathrm{Mn}=40.01 \mathrm{~g} / \mathrm{mol})$, dimethyl formamide (DMF), acetone, and alcohol were supplied by Chemical Reagent Company (Beijing, China).

\subsection{Synthesis of GO/AMT Nanohybrids}

The preparation of GO was achieved by using natural graphite powder through a modified Hummer's method [11,42]. Compared to the previous Hummer's method, the improved method not only controlled the temperature more easily, but also provided better hydrophilicity and a higher oxidation rate of GO. In detail, a certain ratio (9:1) of concentrated $\mathrm{H}_{2} \mathrm{SO}_{4} / \mathrm{H}_{3} \mathrm{PO}_{4}$ was added to the mixture of the graphite flakes $(1.0 \mathrm{~g}), \mathrm{KMnO}_{4}(6.0 \mathrm{~g})$, and $\mathrm{H}_{2} \mathrm{O}_{2}\left(1 \mathrm{~mL}, 30 \% \mathrm{H}_{2} \mathrm{O}_{2}\right.$ solution). The obtained mixture was then centrifuged after stirring. The remaining solid material was washed sequentially with deionized water, $30 \% \mathrm{HCl}$, and ethanol. The resulting solid was filtered and dried under a vacuum at room temperature overnight. Finally, $2.0 \mathrm{~g}$ of product was obtained.

One hundred milligrams of the obtained GO were then suspended in $100 \mathrm{~mL}$ of DMF by sonicating the hybrid for $1 \mathrm{~h}$. After that, $10 \mathrm{mM} \mathrm{mL}^{-1}$ of NHS was added to the above suspension under fast stirring for $20 \mathrm{~min}$. Then, $40 \mathrm{mM} \mathrm{mL}^{-1} \mathrm{EDC}$ was quickly added to the mixture under continuous mixing for $20 \mathrm{~min}$. A total of $10 \mathrm{mM} \mathrm{mL}^{-1}$ of adamantan-1-amine was immediately added to the mixture and stirred for $2 \mathrm{~h}$. The obtained mixture was washed by DMF twice, and then washed by water in order to remove excess EDC, NHS, and the byproduct urea. Finally, the solid was dried in a vacuum oven at $70^{\circ} \mathrm{C}$ for 1 day.

\subsection{Preparation of GO/AMT-CE Composites}

The bisphenol A type $\mathrm{CE}$ was melted in a glass flask at $120^{\circ} \mathrm{C}$. When the resin totally melted, the suitable content $(0 \%, 0.3 \%, 0.5 \%, 0.7 \%$, and $1.0 \%)$ of GO/AMT was added into the resin with high-shear mixing. Then the obtained mixture was put into a preheated mold with a release agent, and then the solvent was removed at $140{ }^{\circ} \mathrm{C}$ under a vacuum condition. The cured procedures were $160^{\circ} \mathrm{C} / 2 \mathrm{~h}+180^{\circ} \mathrm{C} / 3 \mathrm{~h}+200^{\circ} \mathrm{C} / 2 \mathrm{~h}$. Finally, the mold was cooled to room temperature and demolded to get the different specimens of composites (Figure 1).

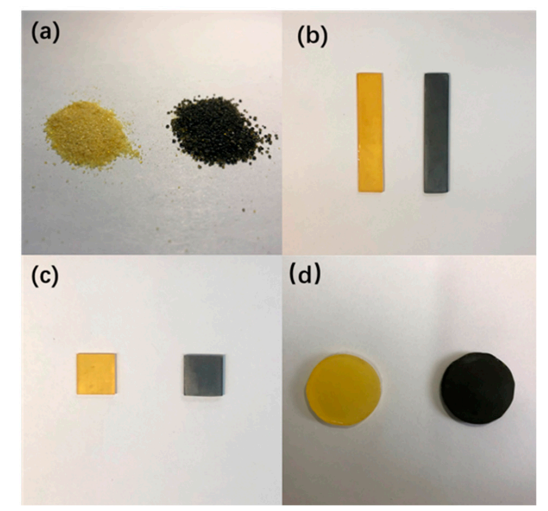

Figure 1. Specimens for (a) thermogravimetric analysis (TGA), (b) mechanical, (c) dielectric, and (d) dynamic thermomechanical analysis (DMA) tests. 


\subsection{Characterization Techniques}

Fourier transform infrared spectroscopy (FT-IR) spectra were recorded on a Perkin-Elmer spectrum GXA model in a range of $4000-550 \mathrm{~cm}^{-1}$ with a resolution of $4 \mathrm{~cm}^{-1}$. Atomic force microscopy (AFM) images were recorded using a NanoWizard 3 NanoScience atomic force microscope (JPK Instruments AG, Berlin, Germany) in tapping mode to identify the thickness of the GO sheets. Transmission electron microscopy (TEM) experiments were performed on a Tecnai G220 transmission electron microscope (FET) with an accelerating voltage of $200 \mathrm{kV}$. GO sheets were dispersed in ethanol by sonication for $30 \mathrm{~min}$, and some pieces were collected on micro-film for TEM observation. Differential scanning calorimetry (DSC) was carried out using a TA instruments DSC Q200. The samples were heated from room temperature to $350{ }^{\circ} \mathrm{C}$ at four different heating rates: $20{ }^{\circ} \mathrm{C} / \mathrm{min}, 15^{\circ} \mathrm{C} / \mathrm{min}, 10{ }^{\circ} \mathrm{C} / \mathrm{min}$, and $5{ }^{\circ} \mathrm{C} / \mathrm{min}$ in $\mathrm{N}_{2}$ atmosphere. Thermogravimetric analysis (TGA) was carried out using a TA instruments TGA Q500 from room temperature to $900{ }^{\circ} \mathrm{C}$ at a heating rate of $10^{\circ} \mathrm{C} / \mathrm{min}$ in $\mathrm{N}_{2}$. Dynamic mechanical properties were determined using a TA instruments dynamic thermomechanical analysis (DMA) Q800 in the three-point bending mode at a frequency of $1 \mathrm{~Hz}$ and a heating rate of $10{ }^{\circ} \mathrm{C} / \mathrm{min}$. The water absorption of the resin was determined by the ISO62:2008. This test was done by putting the cured resin at a temperature of $23.0 \pm 1{ }^{\circ} \mathrm{C}$, and weighting the resin once every $24 \mathrm{~h}$. The dielectric constant was carried out by the Agilent $4294 \mathrm{~A}$ at a frequency from $400 \mathrm{~Hz}$ to $100 \mathrm{MHz}$ at room temperature. Before the test, resin spline should be copper plated. The flexural strength and tensile strength were determined by the Universal Testing Machine (UTM) at room temperature by the national standard they followed.

\section{Results and Discussion}

\subsection{Characteristics of GO/AMT Nanohybrids}

The morphology of GO nanosheets was characterized by AFM and TEM (Figure 2). It can be seen from the AFM image that the thickness of the GO layer is about $1 \mathrm{~nm}$, which is consistent with the previous results [18]. The TEM image further demonstrates the layered structure of GO.

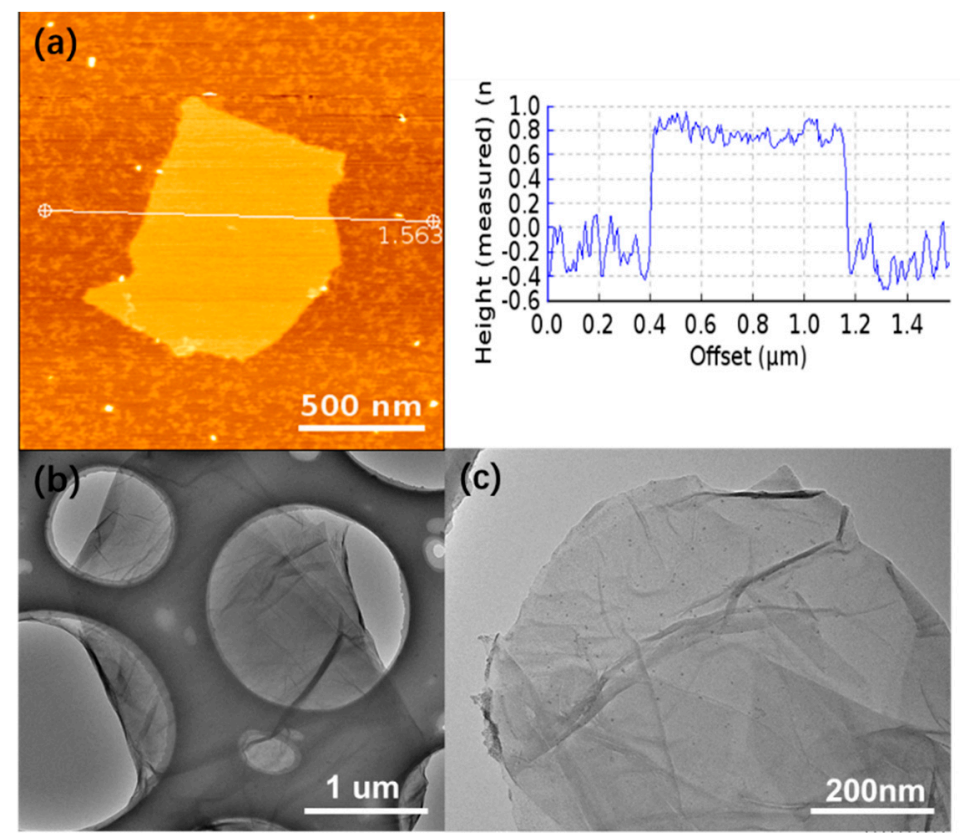

Figure 2. Morphological characterizations of GO and GO/AMT: (a) atomic force microscopy (AFM) height image of GO, (b) transmission electron microscopy (TEM) image of GO, and (c) TEM image of GO/AMT. 
Subsequently, FT-IR and Raman spectroscopy were utilized to compare the difference between GO and GO/AMT nanohybrids (Figure 3). Figure 3a shows the typical FT-IR spectra of GO, GO/AMT, and AMT. In the spectrum of GO, the peak at $3420 \mathrm{~cm}^{-1}$ is related to the $-\mathrm{OH}$ vibration stretching. The peaks at 1720,1620 , and $1142 \mathrm{~cm}^{-1}$ are corresponding to the carboxyl $\mathrm{C}=\mathrm{O}$ stretching, $\mathrm{C}=\mathrm{C}$ stretching of the aromatic ring, epoxy C-O stretching, and epoxy/alkoxy C-O stretching vibration, respectively $[43,44]$. The spectrum of GO shows a peak at $1720 \mathrm{~cm}^{-1}$ that is assigned to the carboxyl $\mathrm{C}=\mathrm{O}$ stretching, which nearly disappears in the spectrum of GO/AMT. In addition, the new peaks of $\mathrm{GO} / \mathrm{AMT}$ spectrum at 1580,1101, and $803 \mathrm{~cm}^{-1}$ correspond to $\mathrm{N}-\mathrm{H}$ bending, $\mathrm{C}-\mathrm{N}$ stretching vibrations, and $\mathrm{C}-\mathrm{H}$ vibrations, respectively [45]. It can be seen that the peaks related to AMT still exist in the spectrum of GO/AMT.
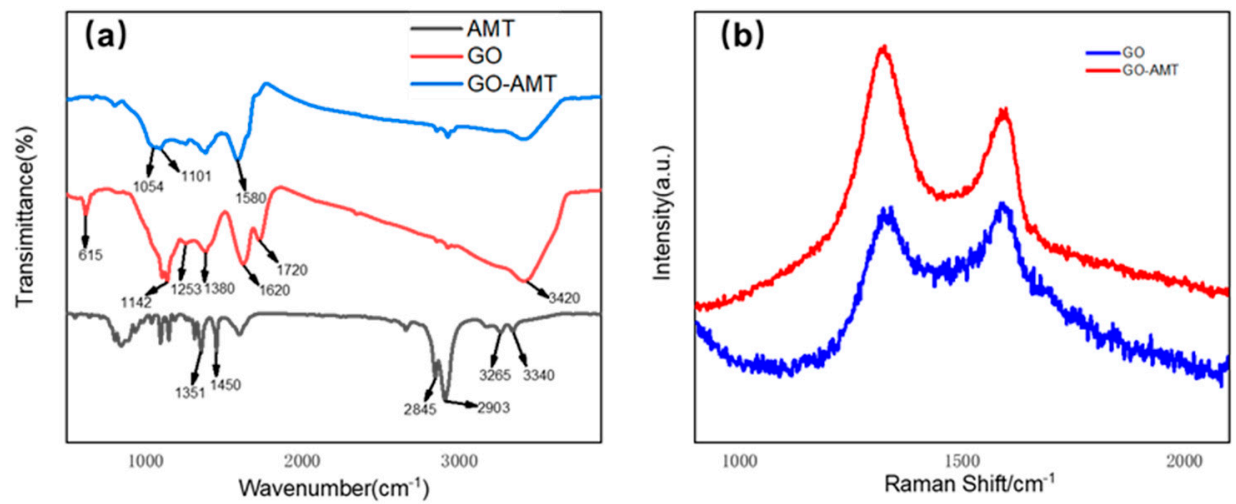

Figure 3. Spectral characterizations of GO and GO-AMT: (a) Fourier transform infrared spectroscopy (FTIR) and (b) Raman Spectra.

Figure $3 b$ shows the Raman spectra of GO and GO/AMT, in which a significant increase in the ratio of $I_{D}$ to $I_{G}$ band intensity can be seen. We suggest that the ratio increase was due to the distortion of the graphene structure caused by the special structure of AMT. Based on the above FT-IR and Raman characterizations, it can be concluded that AMT was successfully attached onto the surface of GO through the diimide-activated amidation reaction.

\subsection{Curing Behavior of GO/AMT-CE Composites}

The curing behavior of materials was investigated by the non-isothermal DSC characterization. Figure 4 shows the curing behaviors of GO/AMT-CE composites by using different weight fractions of GO/AMT nanohybrids. The curing exotherms in the formation of the triazine rings proved the thermal curability of pure CE. It can be seen that the temperature of the curing reaction exothermic peak decreased with the increase of GO/AMT in the composites. The exothermic peak temperature of $1 \% \mathrm{GO} / \mathrm{AMT}-\mathrm{CE}$ was about $100{ }^{\circ} \mathrm{C}$ lower than that of pure $\mathrm{CE}$, which could be attributed to the intensive promotion of the curing reaction of $\mathrm{CE}$ by $-\mathrm{OH}$ groups in the molecule of GO/AMT. In addition, the abundance of active epoxy groups on the surface of GO/AMT also contributed to the formation of rings with -OCN [46].

The initial exothermic peak temperature (Ti), the maximum exothermic peak temperature (Tp), and the final exothermic peak temperature (Tf) of DSC thermograms with a heating rate $\left(10{ }^{\circ} \mathrm{C} / \mathrm{min}\right)$ of different content of GO/AMT-modified CE were measured and shown in Table 1. It can be found that the more GO/AMT added into $\mathrm{CE}$, the lower the exothermic heat $(\Delta \mathrm{H})$ of the reaction occurred at first. When the content of GO/AMT was increased to $1 \mathrm{wt} \%$, the exothermic heat $(\Delta \mathrm{H})$ began to rise up, which was probably due to the increased reaction between GO/AMT and CE resin. The appearance of double peaks may be attributed to the increase of GO/AMT, which complicates the curing mechanism. The curing exothermic peaks of multiple groups ringing become more apparent. 


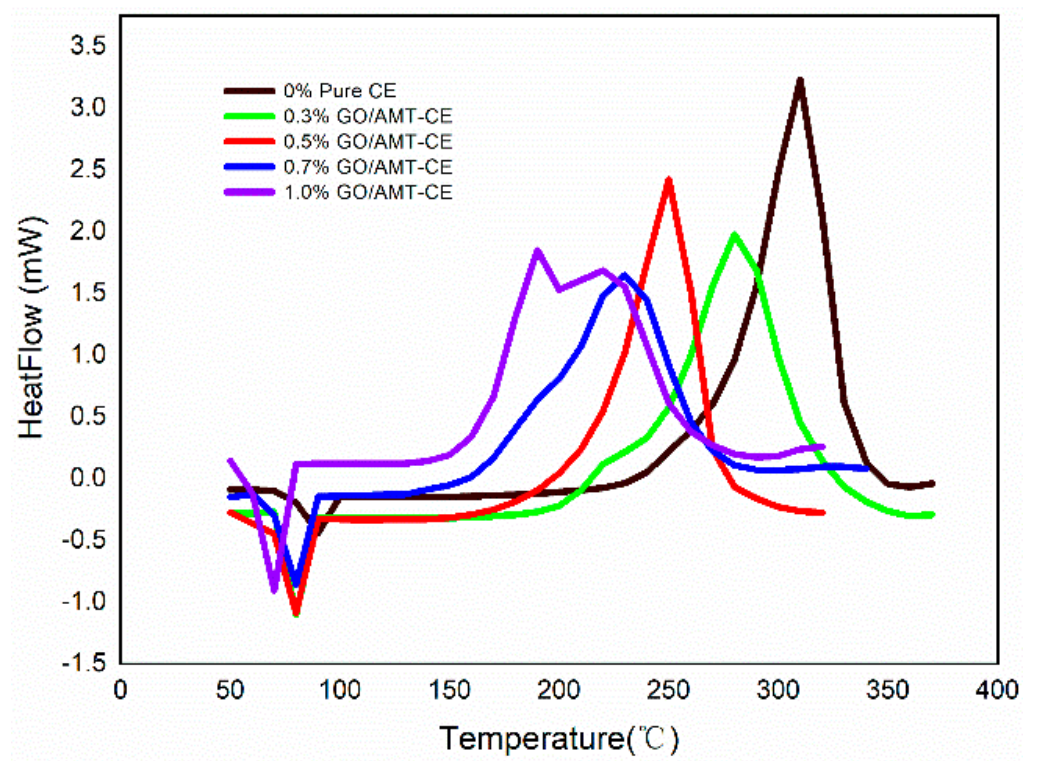

Figure 4. Differential scanning calorimetry (DSC) curves of GO/AMT-CE composites with different GO-AMT contents.

Table 1. Sample formulation and Differential scanning calorimetry (DSC) date of various graphene oxide/adamantane-cyanate ester (GO/AMT-CE) composites at the heating rate of $10{ }^{\circ} \mathrm{C} / \mathrm{min}$.

\begin{tabular}{ccccc}
\hline Samples & $\mathbf{T}_{\mathbf{i}}\left({ }^{\circ} \mathbf{C}\right)$ & $\mathbf{T}_{\mathbf{p}}\left({ }^{\circ} \mathbf{C}\right)$ & $\mathbf{T}_{\mathbf{f}}\left({ }^{\circ} \mathbf{C}\right)$ & $\Delta \boldsymbol{H}(\mathbf{J} / \mathbf{g})$ \\
\hline Pure CE & 267.34 & 310.09 & 332.35 & 828.5 \\
$0.3 \%$ GO/AMT & 233.31 & 281.49 & 321.88 & 794.9 \\
$0.5 \%$ GO/AMT & 207.95 & 250.46 & 272.37 & 669.1 \\
$0.7 \%$ GO/AMT & 176.91 & 229.96 & 264.45 & 600.1 \\
$1.0 \%$ GO/AMT & 163.67 & 189.48 & 258.85 & 671.7 \\
\hline
\end{tabular}

Ti-The initial exothermic peak temperature; Tp-The maximum exothermic peak temperature; Tf-The final exothermic peak temperature.

\subsection{Thermal Properties of GO/AMT-CE Composites}

The thermal stability of the GO/AMT-CE composites was estimated through the TGA measurement. Typical traces with different contents of GO/AMT-CE were performed under nitrogen, as shown in Figure 5, which exhibited a major mass loss from 400 to $550{ }^{\circ} \mathrm{C}$. $\mathrm{Td}_{5} \%$ represented the corresponding temperature when the weight loss was $5 \%$, while $\operatorname{Td}_{10} \%$ referred to $10 \%$. With the increase of GO/AMT in CE resin systems, the temperature of $\mathrm{Td}_{5} \%$ increased from 403 to $431{ }^{\circ} \mathrm{C}$, and the temperature of $\mathrm{Td}_{10 \%}$ increased from 428 to $442{ }^{\circ} \mathrm{C}$. The char yield at $800{ }^{\circ} \mathrm{C}$ of pure CE was $34 \%$, while that of GO/AMT-CE composites was $38-42 \%$. The enhancement of the thermal stability could be mainly ascribed to the excellent thermal stability of GO/AMT and the increasing cross-linking degree of the GO/AMT-CE system under the catalytic effect of GO/AMT in CE resin. Therefore, the mobility of polymer segments at the interface between the GO/AMT and CE matrices was inhibited by strong interactions. 


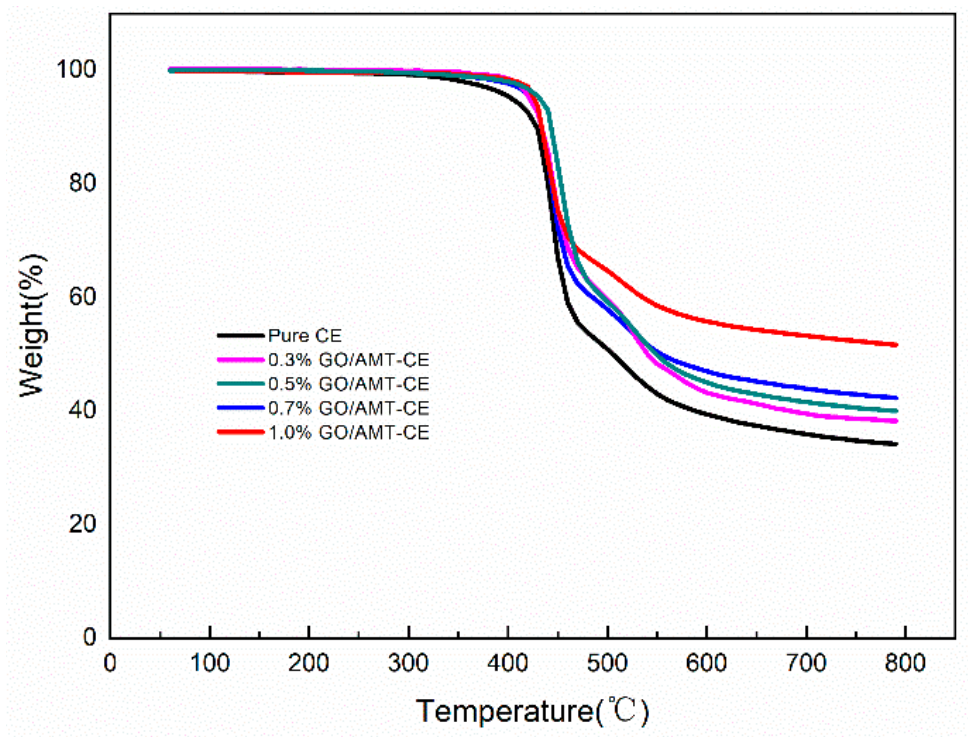

Figure 5. Thermal stability of GO/AMT-CE composites with different GO/AMT contents.

\subsection{Mechanical Properties of GO/AMT-CE Composites}

The mechanical properties of GO/AMT-CE composites were determined by the UTM at room temperature. Figure 6a shows that the addition of GO/AMT can improve the tensile strength of $\mathrm{CE}$ from 30 to $62 \mathrm{Mpa}$, and Figure $6 \mathrm{~b}$ indicates that the elongation at break increases from $2.4 \%$ to $4.8 \%$. In addition, the tensile modulus increased from 1400 to $1600 \mathrm{Mpa}$ (Figure 6c), indicating that the addition of GO/AMT significantly improved the strength and toughness of CE resin.
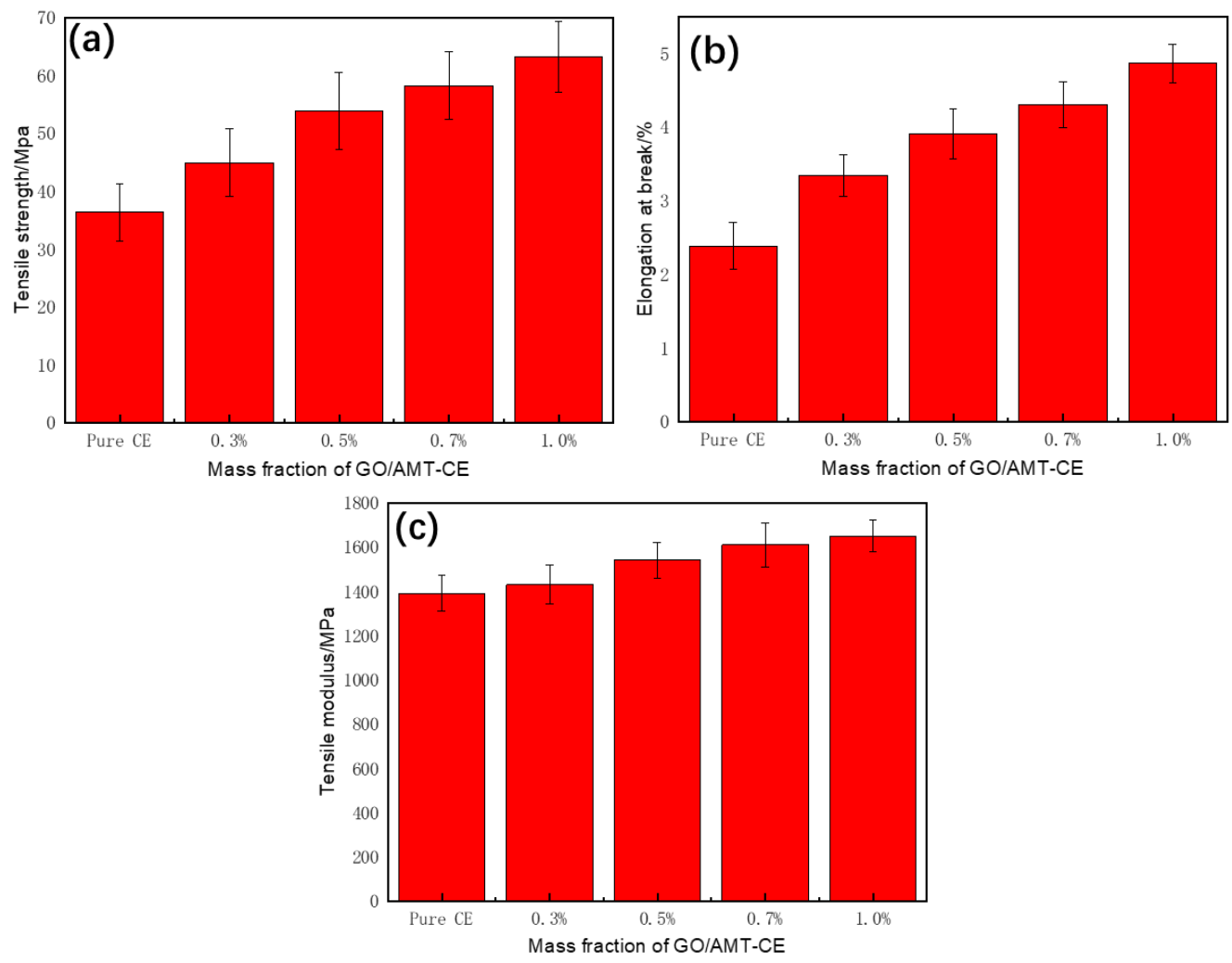

Figure 6. Mechanical properties of GO/AMT-CE with different GO/AMT contents: (a) tensile storage (b) elongation at break, and (c) tensile modulus. 
The mechanical properties of GO/AMT-CE composites under wet-heat conditions were also carried out by putting the resin samples into $23^{\circ} \mathrm{C}$ water for $240 \mathrm{~h}$ (Table 2). From this table, it can be seen that GO/AMT-CE composites had higher wet-heat resistant property compared to pure CE. The significant improvement of mechanical properties was mainly ascribed to the excellent mechanical properties of GO and the interface combination between GO and resin. The epoxy group on the surface of GO formed an oxazolidinone ring with the -NCO of CE resin, thereby forming a more obscure network structure and improving the bonding strength. Moreover, a stronger steric effect resulted in improved dispersibility of GO in the resin matrix in the presence of the AMT structure.

Table 2. The mechanical properties of the dried and wet (upper and lower row, respectively for each material) CE resins modified by GO/AMT.

\begin{tabular}{cccc}
\hline Content & Tensile Strength (Mpa) & Elongation at Break (\%) & Tensile Modulus (Mpa) \\
\hline \multirow{2}{*}{ Pure CE } & $36.3 \pm 5.0$ & $2.38 \pm 0.32$ & $1390 \pm 80$ \\
& $32.7 \pm 4.6$ & $2.18 \pm 0.27$ & $1320 \pm 70$ \\
\hline \multirow{2}{*}{$0.3 \%$ GO/AMT } & $44.9 \pm 5.8$ & $3.37 \pm 0.28$ & $1430 \pm 90$ \\
& $40.2 \pm 5.3$ & $2.80 \pm 0.32$ & $1440 \pm 100$ \\
\hline \multirow{2}{*}{$0.5 \%$ GO/AMT } & $53.8 \pm 6.7$ & $3.90 \pm 0.34$ & $1540 \pm 80$ \\
& $49.1 \pm 5.8$ & $3.22 \pm 0.29$ & $1520 \pm 80$ \\
\hline \multirow{2}{*}{$0.7 \%$ GO/AMT } & $58.2 \pm 5.9$ & $4.30 \pm 0.31$ & $1610 \pm 100$ \\
& $55.7 \pm 5.2$ & $4.13 \pm 0.30$ & $1690 \pm 110$ \\
\hline \multirow{2}{*}{$1.0 \%$ GO/AMT } & $63.1 \pm 6.1$ & $4.86 \pm 0.26$ & $1650 \pm 70$ \\
& $58.2 \pm 5.6$ & $4.65 \pm 0.28$ & $1620 \pm 90$ \\
\hline
\end{tabular}

\subsection{Dielectric Properties of GO/AMT-CE Composites}

The dielectric test was carried out by the Agilent 4294A at a frequency of $400 \mathrm{HZ}$ to $20 \mathrm{MHz}$ under room temperature. The results are shown in Figure 7 and Table 3. It can be observed from Figure 7 that the dielectric constant of GO/AMT modified CE resin was smaller than that of pure $\mathrm{CE}$ resin. At the same time, the dielectric constant decreased with the increase of GO/AMT in CE resin. GO is an insulator, with oxygen atoms randomly attached on graphene sites, which undergo conversion from sp2-hybridized carbon atoms in graphene to sp3-hybridized carbon in GO. In addition to exhibiting low Dk values for these materials, GO sheets are used as interlayers in the polymer matrix because the GO homogeneity is not as great as that of grapheme, hence, there is much less electron mobility. This process reduces conjugation and confines p-electrons [47], resulting in very low-dielectric constant values of GO. For example, Wang et al. proposed an effective approach that used in situ polymerization to fabricate large-area GO/polyimide (PI) composite films. The results showed the bulk dielectric constant decreased from 3.3, for the neat PI film, to just 2.0 for the PI-ODA-GO composite film [48]. Zhang et al. reported an efficient and novel method to functionalize GO with hyperbranched polysiloxane and successfully compounded them with $\mathrm{CE}$ resin to prepare nanocomposites. The study showed a lower and more stable dielectric constant and loss than pure CE resin over the testing frequency from 10 to $60 \mathrm{MHz}$ [41]. In addition, the adamantyl group that possessed a cage structure of the whole aliphatic had a lower polarization, which effectively increased the large free volume of polymer. We suggest that both polarization and free volume of polymer are crucial for the dielectric constant. For instance, the increase of the free volume and the reduction of the polarization will reduce the dielectric constant of polymer.

Table 3. Dielectric properties of GO/AMT-CE composites with different GO/AMT contents.

\begin{tabular}{cccc}
\hline Sample & Dielectric Constant (at 1 MHz) & Dielectric Constant Decrease & Dielectric Loss (at 1 MHz) \\
\hline Pure CE & 3.9465 & - & 0.0122 \\
$0.3 \%$ GO/AMT & 3.7472 & -0.1993 & 0.0105 \\
$0.5 \%$ GO/AMT & 3.1843 & -0.5629 & 0.0098 \\
$0.7 \%$ GO/AMT & 2.8837 & -0.3006 & 0.0072 \\
$1.0 \%$ GO/AMT & 2.5437 & -0.3400 & 0.0063 \\
\hline
\end{tabular}




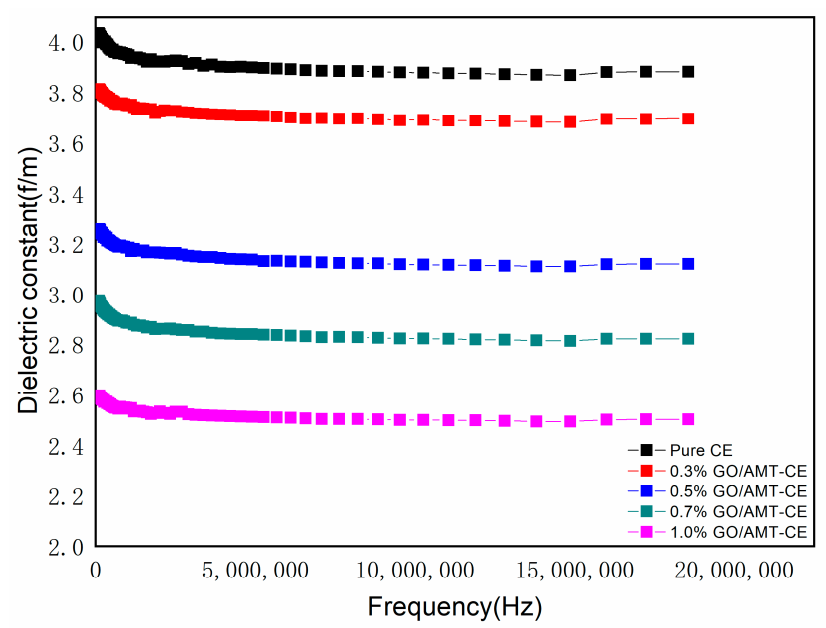

Figure 7. Dielectric constants of GO/AMT-CE composites with different GO/AMT contents.

In addition, good adhesion between GO/AMT and CE resin will reduce interfacial polarization and limit the mobility of the segments, resulting in the decrease of the dielectric constant. As a result, we suggest that the obtained composites be equipped with excellent dielectric property.

\subsection{Water Absorption of GO/AMT-CE Composites}

The water absorption of the GO/AMT-CE composites was determined by putting the cured composites into water and heating to $23.0 \pm 1{ }^{\circ} \mathrm{C}$, and weighting the resin every $24 \mathrm{~h}$. Figure 8 shows the water absorption of GO/AMT-CE composites with different GO/AMT contents. It can be seen that the water absorption of pure $\mathrm{CE}$ is the strongest, and the water absorption was reduced with the increase of GO/AMT content in the $\mathrm{CE}$ resin. We suggest that one possible reason is the above mentioned improved curing degree. A large number of functional groups on the surface of GO can increase the compatibilization at the organic/inorganic interface, which can also effectively prevent water from entering the network structure of the composites. Another reason might be attributed to the increase of the high polar sites of the adamantyl group of the system. It is possible that the addition of adamantyl groups can effectively decrease the water absorption of the systems.

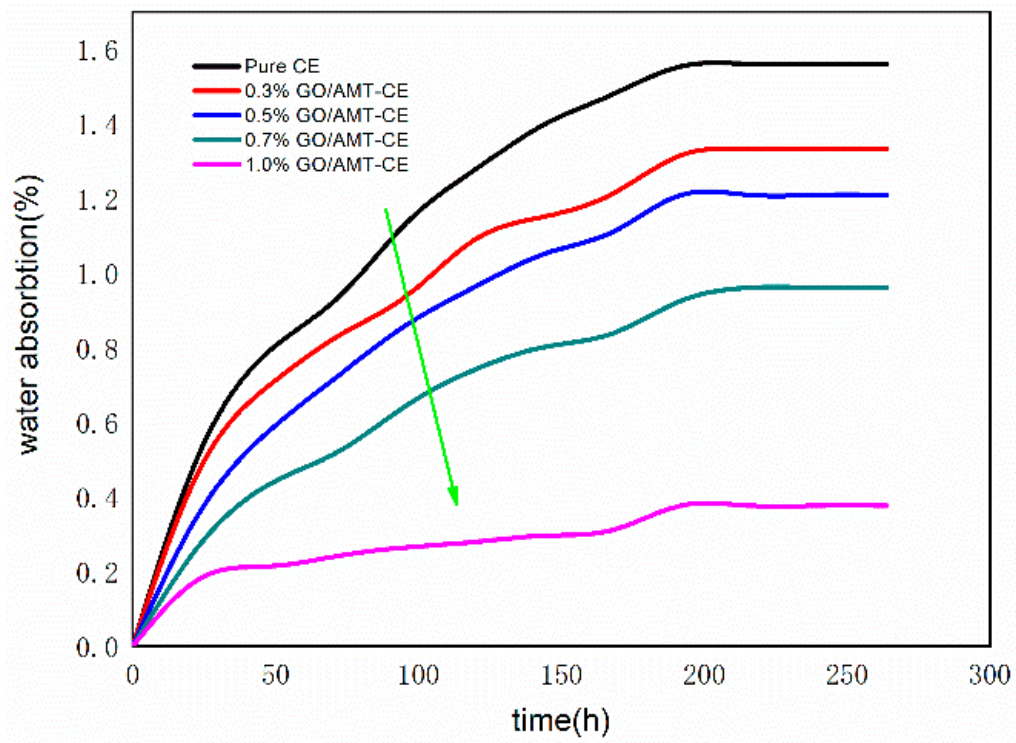

Figure 8. Water absorption of GO/AMT-CE composites with different GO/AMT contents. 


\section{Conclusions}

In summary, we successfully obtained novel GO/AMT nanohybrids by attaching AMT onto GO nanosheets by the amidation reaction. Subsequently, GO/AMT nanohybrids were utilized to modify the CE resin to create functional GO/AMT-CE composites. The thermal, mechanical, dielectric, and water resistant properties of the fabricated GO/AMT-CE composites were studied. It was found that GO/AMT greatly improved the properties of CE resin. The exothermic peak temperature of $1 \%$ GO/AMT-CE was around $100{ }^{\circ} \mathrm{C}$ lower than the pure CE. The char yield at $800{ }^{\circ} \mathrm{C}$ of pure $\mathrm{CE}$ was $34 \%$, while that of GO/AMT-CE composites increased to 38-42\%. GO/AMT can improve the tensile strength of CE from 30 to $62 \mathrm{Mpa}$, increase the elongation at break from $2.4 \%$ to $4.8 \%$, and increase the tensile modulus from 1400 to $1600 \mathrm{Mpa}$. In addition, the dielectric constant decreased from 3.94 to 2.99 under $1 \mathrm{MHz}$. This study provides a potential way to fabricate novel CE resins by using polymer-functionalized graphene materials.

Author Contributions: Z.M. and J.S. designed and performed the experiments; J.S. and P.L. analyzed the data; Z.S. and G.W. contributed experimental materials and analysis tools; T.L. and Z.S. optimized the data analysis; Z.M. wrote the paper under the supervision of P.L., Z.S., and G.W.

Funding: This work was funded by the National Natural Science Foundation of China (NSFC, grant no. 51573013 51873016, and 51873225).

Acknowledgments: The authors gratefully acknowledge the financial support from the National Natural Science Foundation of China (NSFC, Grant no. 51573013, 51873016, and 51873225).

Conflicts of Interest: The authors declare no conflict of interest.

\section{References}

1. Iijima, T.; Katsurayama, S.; Fukuda, W.; Tomoi, M. Modification of cyanate ester resin by poly(ethylene phthalate) and related copolyesters. J. Appl. Polym. Sci. 2015, 76, 208-219. [CrossRef]

2. Kimura, H.; Ohtsuka, K.; Matsumoto, A. New thermosetting resin from benzoxazine and cyanate ester resin. Adv. Polym. Tech. 2013, 32, 651-659. [CrossRef]

3. Zhao, C.B.; Xu, S.C.; Qin, Y.F.; Su, L.; Yang, X.J. Thermal conductivity cyanate ester resin composites filled with boron nitride. Adv. Mater. Res. 2014, 893, 259-262. [CrossRef]

4. Xiao, W.; Jie, J.; Mo, S. Cyanate ester resin/graphene nanocomposite: Curing dynamics and network formation. Eur. Polym. J. 2012, 48, 1034-1041.

5. Hu, J.T.; Gu, A.; Liang, G.; Zhuo, D.; Li, Y. Synthesis of mesoporous silica and its modification of bismaleimide/cyanate ester resin with improved thermal and dielectric properties. Polym. Adv. Technol. 2012, 23, 454-462. [CrossRef]

6. Prokopec, R.; Humer, K.; Maix, R.K.; Fillunger, H.; Weber, H.W. Mechanical strength of various cyanate ester/epoxy insulation systems after fast neutron irradiation to the iter design fluence and beyond. Fusion Eng. Des. 2007, 82, 1508-1512. [CrossRef]

7. Goertzen, W.K.; Kessler, M.R. Thermal and mechanical evaluation of cyanate ester composites with low-temperature processability. Compos. Part A-Appl. Sci. Manuf. 2007, 38, 779-784. [CrossRef]

8. Zhuo, D.; Gu, A.; Liang, G.; Hu, J.T.; Cao, L.; Yuan, L. Flame retardancy and flame retarding mechanism of high performance hyperbranched polysiloxane modified bismaleimide/cyanate ester resin. Polym. Degrad. Stab. 2011, 96, 505-514. [CrossRef]

9. Devaraju, S.; Vengatesan, M.R.; Selvi, M.; Song, J.K.; Alagar, M. Mesoporous silica reinforced cyanate ester nanocomposites for low k dielectric applications. Microporous Mesoporous Mater. 2013, 179, $157-164$. [CrossRef]

10. Yuan, L.; Huang, S.; Gu, A.; Liang, G.; Chen, F.; Hu, Y.; Nutt, S. A cyanate ester/microcapsule system with low cure temperature and self-healing capacity. Compos. Sci. Technol. 2013, 87, 111-117. [CrossRef]

11. Zhao, X.; Li, Y.; Wang, J.; Ouyang, Z.; Li, J.; Wei, G.; Su, Z. Interactive oxidation-reduction reaction for the in situ synthesis of graphene-phenol formaldehyde composites with enhanced properties. Acs Appl. Mater. Interfaces 2014, 6, 4254-4263. [CrossRef] [PubMed] 
12. Iijima, T.; Kunimi, T.; Oyama, T.; Tomoi, M. Modification of cyanate ester resin by soluble polyarylates. Polym. Int. 2010, 88, 1-11. [CrossRef]

13. Zhang, Z.P.; Pei, J.Z.; Fang, C.Q.; Chen, S.F. Modification of cyanate ester resin by epoxy-functionalized polyhedral oligomeric silsesquioxane. Adv. Mater. Res. 2012, 549, 314-317. [CrossRef]

14. Zeng, M.; Lu, C.; Wang, B.; Qi, C. Free volume hole size of cyanate ester resin/epoxy resin interpenetrating networks and its correlations with physical properties. Radiat. Phys. Chem. 2010, 79, 966-975. [CrossRef]

15. Liang, G.; Zhang, M. Enhancement of processability of cyanate ester resin via copolymerization with epoxy resin. J. Appl. Polym. Sci. 2010, 85, 2377-2381. [CrossRef]

16. Karad, S.K.; Attwood, D.; Jones, F.R. Moisture absorption by cyanate ester modified epoxy resin matrices. Part iv: Effect of curing schedules. Polym. Compos. 2010, 24, 567-576. [CrossRef]

17. Yu, X.; Lin, D.; Li, P.; Su, Z. Recent advances in the synthesis and energy applications of tio 2-graphene nanohybrids. Sol. Energy Mater Sol. Cells 2017, 172, 252-269. [CrossRef]

18. Li, Y.; Zhao, X.; Zhang, P.; Jing, N.; Li, J.; Su, Z.; Wei, G. A facile fabrication of large-scale reduced graphene oxide-silver nanoparticle hybrid film as a highly active surface-enhanced raman scattering substrate. J. Mater. Chem. C 2015, 3, 4126-4133. [CrossRef]

19. Li, D.; Liu, T.; Yu, X.; Di, W.; Su, Z. Fabrication of graphene-biomacromolecule hybrid materials for tissue engineering application. Polym. Chem. 2017, 8, 4309-4321. [CrossRef]

20. Lin, D.; Su, Z.; Wei, G. Three-dimensional porous reduced graphene oxide decorated with $\mathrm{MoS}_{2}$ quantum dots for electrochemical determination of hydrogen peroxide. Mater. Today Chem. 2018, 7, 76-83. [CrossRef]

21. Zhang, M.; Yang, L.; Su, Z.; Wei, G. Recent advances in the synthesis and applications of graphene-polymer nanocomposites. Polym. Chem. 2015, 6, 6107-6124. [CrossRef]

22. Yu, X.; Zhang, W.; Zhang, P.; Su, Z. Fabrication technologies and sensing applications of graphene-based composite films: Advances and challenges. Biosens. Bioelectron. 2017, 89, 72-84. [CrossRef] [PubMed]

23. Zhao, X.; Zhang, P.; Chen, Y.; Su, Z.; Wei, G. Recent advances in the fabrication and structure-specific applications of graphene-based inorganic hybrid membranes. Nanoscale 2015, 7, 5080-5093. [CrossRef] [PubMed]

24. Li, Y.; Zhang, P.; Ouyang, Z.; Zhang, M.; Lin, Z.; Li, J.; Su, Z.; Wei, G. Nanoscale graphene doped with highly dispersed silver nanoparticles: Quick synthesis, facile fabrication of $3 \mathrm{~d}$ membrane-modified electrode, and super performance for electrochemical sensing. Adv. Funct. Mater. 2016, 26, 2122-2134. [CrossRef]

25. Liu, W.; Zhang, X.; Zhou, L.; Shang, L.; Su, Z. Reduced graphene oxide (rgo) hybridized hydrogel as a near-infrared (nir)/ph dual-responsive platform for combined chemo-photothermal therapy. J. Colloid Interface Sci. 2019, 536, 160-170. [CrossRef] [PubMed]

26. Li, K.; Zhang, Z.; Li, D.; Zhang, W.; Yu, X.; Liu, W.; Gong, C.; Wei, G.; Su, Z. Biomimetic ultralight, highly porous, shape-adjustable, and biocompatible 3D graphene minerals via incorporation of self-assembled peptide nanosheets. Adv. Funct. Mater. 2018, 28, 1801056. [CrossRef]

27. Xue, Y.; Liu, Y.; Lu, F.; Qu, J.; Chen, H.; Dai, L. Functionalization of graphene oxide with polyhedral oligomeric silsesquioxane (poss) for multifunctional applications. J. Phys. Chem. Lett. 2012, 3, 1607-1612. [CrossRef] [PubMed]

28. Liu, H.; Bandyopadhyay, P.; Kim, N.H.; Moon, B.; Lee, J.H. Surface modified graphene oxide/poly(vinyl alcohol) composite for enhanced hydrogen gas barrier film. Polym. Test. 2016, 50, 49-56. [CrossRef]

29. Rui, D.; Liu, L. Preparation and properties of acrylic resin coating modified by functional graphene oxide. Appl. Surf. Sci. 2016, 368, 378-387.

30. Mazzoli, A.; Corinaldesi, V.; Donnini, J.; Perna, C.D.; Micheli, D.; Vricella, A.; Pastore, R.; Bastianelli, L.; Moglie, F.; Primiani, V.M. Effect of graphene oxide and metallic fibers on the electromagnetic shielding effect of engineered cementitious composites. J. Build. Eng. 2018, 18, 33-39. [CrossRef]

31. Barkakaty, B.; Matsumoto, K.; Endo, T. Synthesis and radical polymerization of adamantyl methacrylate monomers having hemiacetal moieties. Macromolecules 2009, 42, 9481-9485. [CrossRef]

32. Oliveira, F.S.; Freire, M.G.; Pratas, M.J.; Pauly, J.; Daridon, J.L.; Marrucho, I.M.; Coutinho, J.A.P. Solubility of adamantane in phosphonium-based ionic liquids. J. Chem. Eng. Data 2012, 55, 662-665. [CrossRef]

33. Rybalko, S.; Nesterova, N.; Diadiun, S.; Danylenko, G.; Danylenko, V.; Guzhova, S.; Maksimov, Y.; Arkadiev, V.; Ivans'Ka, N.; Maksymenok, O. Therapeutical effect of modified adamantane copolymer compounds: Study of molecular mechanisms. Acta Biochim. Pol. 2001, 48, 241-249. [PubMed] 
34. Saeed, A.; Erben, M.F.; Bolte, M. Synthesis, structural and vibrational properties of 1-(adamantane-1carbonyl)-3-halophenyl thioureas. Spectrochim. Acta A 2013, 102, 408. [CrossRef] [PubMed]

35. Mathias, L.J.; Tullos, G.L. Synthesis of adamantyl and benzoxazole substituted poly( m-phenylene)s via the nickel catalysed coupling of aryl chlorides. Polymer 1996, 37, 3771-3774. [CrossRef]

36. Hsiao, S.H.; Li, C.T. Synthesis and characterization of new adamantane-based polyimides. Macromolecules 1998, 31, 1435-1442. [CrossRef]

37. Liaw, D.J.; Liaw, B.Y. Synthesis and characterization of new polyamide-imides containing pendent adamantyl groups. Polymer 2001, 42, 839-845. [CrossRef]

38. Su, Y.-C.; Chen, W.-C.; Chang, F.-C. Preparation and characterization of polyseudorotaxanes based on adamantane-modified polybenzoxazines and $\beta$-cyclodextrin. Polymer 2005, 46, 1617-1623. [CrossRef]

39. Šilhár, P.; Silvaggi, N.R.; Pellett, S.; Čapková, K.; Johnson, E.A.; Allen, K.N.; Jandt, K.D. Evaluation of adamantane hydroxamates as botulinum neurotoxin inhibitors: Synthesis, crystallography, modeling, kinetic and cellular based studies. Bioorg. Med. Chem. 2013, 21, 1344-1348. [CrossRef] [PubMed]

40. Lin, Q.; Qu, L.; Lu, Q.; Fang, C. Preparation and properties of graphene oxide nanosheets/cyanate ester resin composites. Polym. Test. 2013, 32, 330-337. [CrossRef]

41. Zhang, M.M.; Yan, H.X.; Gong, C.; Zhang, F.F. Hyperbranched polysiloxane functionalization of graphene oxide for improved mechanical properties of cyanate ester nanocomposites. J. Compos. Mater. 2015, 49, 939-948. [CrossRef]

42. Marcano, D.C.; Kosynkin, D.V.; Berlin, J.M.; Alexander, S.; Zhengzong, S.; Alexander, S.; Alemany, L.B.; Wei, L.; Tour, J.M. Improved synthesis of graphene oxide. Acs Nano 2010, 4, 4806. [CrossRef] [PubMed]

43. Acik, M.; Lee, G.; Mattevi, C.; Pirkle, A.; Wallace, R.M.; Chhowalla, M.; Cho, K.; Chabal, Y. The role of oxygen during thermal reduction of graphene oxide studied by infrared absorption spectroscopy. J. Phys. Chem. C 2015, 115, 19761-19781. [CrossRef]

44. Acik, M.; Lee, G.; Mattevi, C.; Chhowalla, M.; Cho, K.; Chabal, Y.J. Unusual infrared-absorption mechanism in thermally reduced graphene oxide. Nat. Mater. 2010, 9, 840-845. [CrossRef] [PubMed]

45. Ramanathan, T.; Fisher, F.T.; Ruoff, R.S.; Brinson, L.C. Amino-functionalized carbon nanotubes for binding to polymers and biological systems. Chem. Mater. 2011, 17, 1290-1295. [CrossRef]

46. Fang, R.; Zhu, G.; Ren, P.; Wang, Y.; Cui, X. In situ polymerization of graphene oxide and cyanate ester-epoxy with enhanced mechanical and thermal properties. Appl. Surf. Sci. 2014, 316, 549-557.

47. Mkhoyan, K.A.; Contryman, A.W.; Silcox, J.; Stewart, D.A.; Eda, G.; Mattevi, C.; Miller, S.; Chhowalla, M. Atomic and electronic structure of graphene-oxide. Microsc. Microanal. 2009, 16, 1704-1705. [CrossRef]

48. Wang, J.Y.; Yang, S.Y.; Huang, Y.L.; Tien, H.W.; Chin, W.K.; Ma, C.C.M. Preparation and properties of graphene oxide/polyimide composite films with low dielectric constant and ultrahigh strength via in situ polymerization. J. Mater. Chem. 2011, 21, 13569-13575. [CrossRef] 